\title{
Rich micronutrient fortification of locally produced infant food does not improve mental and motor development of Zambian infants: a randomised controlled trial
}

\author{
Daniela Manno $^{1 *}$, Priscilla K. Kowa ${ }^{2}$, Hellen K. Bwalya ${ }^{2}$, Joshua Siame ${ }^{2}$, Sally Grantham-McGregor ${ }^{3}$, \\ Kathy Baisley ${ }^{1}$, Bianca L. De Stavola ${ }^{1}$, Shabbar Jaffar ${ }^{1}$ and Suzanne Filteau ${ }^{1}$ \\ ${ }^{1}$ London School of Hygiene and Tropical Medicine, London, UK \\ ${ }^{2}$ University Teaching Hospital, Lusaka, Zambia \\ ${ }^{3}$ Institute of Child Health, London, UK
}

(Received 24 August 2010 - Revised 10 May 2011 - Accepted 11 May 2011 - First published online 5 July 2011)

\begin{abstract}
It is uncertain whether multiple micronutrients benefit the mental and psychomotor development of young children in developing countries. We conducted a randomised double-blind controlled trial to evaluate the effect of a richly micronutrient-fortified $v$. a basal fortified porridge on mental and psychomotor development in Zambian infants. Infants ( $n$ 743) were randomised at age 6 months to receive either the richly fortified or the basal fortified infant food and were followed up until 18 months of age. All the infants were evaluated monthly for achievement of a series of developmental milestones. The Bayley scales of infant development II were administered to a subsample of 502 infants at 6,12 and 18 months. Rich micronutrient fortification had no significant benefit on the following: (a) number of developmental milestones achieved (rate ratio at 12 months $=1 \cdot 00 ; 95 \%$ CI 0.96, 1.05; $P=0 \cdot 81$, adjusted for sex, socio-economic status and maternal education, with similar results at 15 and 18 months); (b) ages of walking unsupported (hazard ratio (HR) 1.04; 95\% CI 0.88, 1.24; $P=0.63$, adjusted for the above covariates) and of speaking three or four clear words (HR 1.01; $95 \%$ CI $0 \cdot 84,1 \cdot 20 ; P=0 \cdot 94$, adjusted for the above covariates); (c) mental development index (MDI) and psychomotor development index (PDI) of the Bayley scales (scores difference adjusted for baseline scores, age at the assessment, sex, socio-economic status, maternal education, language, age and HIV status: MDI $0 \cdot 3$ (95\% CI $-0 \cdot 5,1 \cdot 1), P=0.43$; PDI $-0.1(95 \% \mathrm{CI}-0 \cdot 9,0 \cdot 7), P=0 \cdot 78)$. In conclusion, the results do not support the hypothesis that rich micronutrient fortification improves Zambian infants' mental and motor development.
\end{abstract}

Key words: Micronutrient-fortified food: Mental and psychomotor development: Bayley scales of infant development: Developmental milestones

In many developing countries, Fe and iodine deficiencies have a detrimental effect on early childhood development ${ }^{(1)}$. Poor levels of cognitive function on entering school are associated with reduced educational attainment that may subsequently affect productivity in adult life ${ }^{(2)}$. Many other micronutrients are deficient in developing countries including vitamins $\mathrm{A}$, $\mathrm{B}_{12}, \mathrm{D}, \mathrm{E}$, riboflavin and $\mathrm{Zn}^{(3)}$, and nutrition programmes have started to use multiple micronutrients. However, the benefit to child development of multiple micronutrients is not clear.

In a recent systematic review and meta-analysis, multiple micronutrient supplementation was associated with small increases in certain cognitive functions in school children ${ }^{(4)}$. In children younger than 5 years, only a few studies have investigated the effect of multiple micronutrient interventions, with conflicting results: four trials in Ghana ${ }^{(5)}$ Bangladesh $^{(6)}$, South Africa ${ }^{(7)}$ and Zanzibar ${ }^{(8)}$ found better motor development in the arms receiving multiple micronutrients, two trials in $\mathrm{Nepal}^{(9)}$ and India ${ }^{(10)}$ did not find any effect of multiple micronutrient supplementation on motor development and on both mental and motor development, respectively. One trial in Indonesia found worse mental development performance in an 18-month-old cohort but no effect in 12 month olds compared with control infants ${ }^{(11)}$.

Micronutrient deficiencies are common in Zambia and micronutrient-rich foods are often expensive and unaffordable ${ }^{(12,13)}$. Programmes of universal fortification of sugar with vitamin A and salt with iodine have been established ${ }^{(12)}$.

Abbreviations: BSID, Bayley scales of infant development; CIGNIS, Chilenje Infant Growth, Nutrition and Infection Study; MDI, mental development index; PDI, psychomotor development index; SES, socio-economic status.

*Corresponding author: Dr Daniela Manno, fax +44 207958 811, email daniela.manno@1shtm.ac.uk 
However, the first 2 years of life are a period of rapid growth and development and available complementary foods may not meet the children's needs ${ }^{(14)}$. Specialised interventions are needed to increase the quality of complementary foods in this group.

We have conducted a randomised double-blind controlled trial of the efficacy of two locally produced complementary/ replacement foods, fortified with different levels of micronutrients, for infants aged 6 to 18 months. The primary outcome was the prevalence of stunting at 18 months and the results were recently published ${ }^{(15)}$. The rich micronutrient fortification did not reduce stunting but did improve Fe status and reduce anaemia ${ }^{(15)}$. The present paper describes the secondary outcome of mental and motor development assessed on developmental milestones and the Bayley scales at 12 and 18 months.

\section{Materials and methods}

\section{Study design}

The Chilenje Infant Growth, Nutrition and Infection Study (CIGNIS) was a randomised double-blind controlled clinical trial. The study is registered as ISRCTN37460449 (http:// www.controlled-trials.com/mrct). Children were randomised to one of two locally produced porridges at age 6 months, and were followed monthly for 12 months.

\section{Study population and recruitment}

The trial was conducted in Chilenje, Lusaka, Zambia, from October 2005 to July 2009. Infants were recruited by approaching mothers attending the child health section of the government clinic on the same site as the project clinic. As over $90 \%$ of Lusaka women take their infants to the clinic for monthly weighing and standard vaccinations ${ }^{(16)}$, the population approached for participation in the study was representative of the area. Infants were eligible if they were aged 6 months ( \pm 2 weeks), in generally good health and their mothers gave written consent to attend monthly clinic visits for the next year, feed their infants the allocated porridge and have their infant undergo project tests. Knowledge of maternal HIV status was not a requirement for joining the study but $90 \%$ of women knew their status from antenatal HIV antibody testing in the government health service.

\section{Randomisation}

Individual randomisation was in blocks of twenty; the code was held by the project Data Safety and Monitoring Board. Each $1 \mathrm{~kg}$ bag of porridge flour was labelled with the participant identifier (ID) number. At the recommendation of the Data Safety and Monitoring Board, an independent observer audited the randomisation and labelling process halfway through the study and found it to be robust, accurate and able to maintain blinding of other study staff and participants. Infants were allocated to porridges by sequential numbers on recruitment. There was one protocol violation: during May and June 2007, one porridge ran out but staff continued to recruit to the other porridge group; sixty-eight children were thus not appropriately randomised. For ethical reasons, they were followed in the study but are not included in the present analyses.

\section{Intervention}

The two porridges, based on local products, were similar in bulk ingredients and macronutrient content but differed in micronutrient content (Table 1). In pilot work, they were found to be acceptable ${ }^{(17)}$ by the local population and to displace other micronutrient-poor complementary or family foods but not to displace breast milk intake ${ }^{(18)}$. The energy density of the porridge prepared according to package directions (equivalent to $30 \mathrm{~g}$ blended in $250 \mathrm{ml}$ water) was $3 \cdot 18 \mathrm{~kJ}$ $(0.76 \mathrm{kcal}) / \mathrm{g}^{(18)}$; protein represented $16 \%$ of energy. The richly fortified porridge contained micronutrients to meet the WHO estimated needs for infants aged 9-11 months with low breast milk intake, assuming an intake of $50 \mathrm{~g}$ flour $/ \mathrm{d}^{(19)}$. The basal porridge had micronutrients at levels that would be in the maize component if national maize fortification which was planned when we started the study were introduced ${ }^{(12,20)}$, which has not occurred. Micronutrient premixes for both flours were prepared by DSM (Isando, South Africa).

Table 1. Composition of trial porridge flours

\begin{tabular}{|c|c|c|}
\hline & $\begin{array}{l}\text { Basal fortification } \\
\text { (per kg flour) }^{*}\end{array}$ & $\begin{array}{l}\text { Rich fortification } \\
\text { (per kg flour) } \dagger\end{array}$ \\
\hline Maize $(g)$ & 650 & 615 \\
\hline Groundnuts (g) & 150 & 150 \\
\hline Bambaranuts (g) & 50 & 50 \\
\hline Beans (white and yellow) (g) & 150 & 150 \\
\hline Vitamin A (mg) & 0.65 & 6.5 \\
\hline Vitamin C (g) & - & $2 \cdot 0$ \\
\hline Vitamin D (mg) & - & 0.1 \\
\hline Thiamin (mononitrate) (mg) & $1 \cdot 3$ & 9 \\
\hline Riboflavin (mg) & 1.6 & 11.2 \\
\hline Niacin (niacinamide) (mg) & 13 & 140 \\
\hline Pyridoxine (HCl) (mg) & 1.6 & $8 \cdot 6$ \\
\hline Folate $(\mathrm{mg})$ & 0.65 & $2 \cdot 21$ \\
\hline Vitamin $B_{12}(\mu \mathrm{g})$ & $3 \cdot 25$ & $9 \cdot 75$ \\
\hline Pantothenic acid (mg) & - & $40 \cdot 3$ \\
\hline Mg (oxide) (g) & - & 0.94 \\
\hline $\mathrm{Fe}$ (ferrous fumarate) $\ddagger(\mathrm{mg}$ ) & $6 \cdot 5$ & 250 \\
\hline Zn (oxide) $\ddagger(\mathrm{mg})$ & 9.75 & 200 \\
\hline $\mathrm{Cu}$ (gluconate) (mg) & - & $3 \cdot 2$ \\
\hline $\mathrm{Mn}$ (sulfate monohydrate) (mg) & - & $12 \cdot 0$ \\
\hline Se (sodium selenite) $(\mathrm{mg})$ & - & 0.2 \\
\hline $\mathrm{Ca}\left(\mathrm{CaH}\left(\mathrm{PO}_{4}\right) \cdot 2 \mathrm{H}_{2} \mathrm{O}\right) \ddagger(\mathrm{g})$ & - & $6 \cdot 8$ \\
\hline $\mathrm{P}\left(\mathrm{CaH}\left(\mathrm{PO}_{4}\right) \cdot 2 \mathrm{H}_{2} \mathrm{O}\right)(\mathrm{g})$ & - & $5 \cdot 3$ \\
\hline
\end{tabular}

* Based on estimated amounts of micronutrients that would be available from $50 \mathrm{~g}$ porridge flour/d made with maize fortified at levels planned nationally for Zambia. Overages (usually $10 \%$ ) added to allow for losses during processing.

† Based on total estimated micronutrient needs of infants aged 9-11 months minus amounts expected from low breast milk intakes ${ }^{(19)}$ and assuming intake of $50 \mathrm{~g}$ porridge flour/d. Exceptions to the micronutrient levels are that vitamin $\mathrm{C}$ was increased to compensate for low Fe bioavailability and $\mathrm{Zn}$ was based on the recommended daily allowance set by the International Zinc Consultative Group in $2004^{(38)}$. Overages (usually $10 \%$ ) added to allow for losses during processing.

$\ddagger$ Phytate was analysed in two batches of each flour and averaged $5.8 \mathrm{~g} / \mathrm{kg}$. This translated into phytate:Zn molar ratios of about 19 in the basal flour and about 3.3 in the richly fortified flour and phytate:Fe molar ratios of 5.6 and 1.7 in the two flours, respectively. 


\section{Adherence}

Women were given $4 \mathrm{~kg}$ of porridge flour each month and could return for more as required. They were instructed to prepare the porridge according to the directions on the package, using a plastic cup, graduated in $\mathrm{ml}$, supplied by the investigators. Adherence was determined through monthly questioning of mothers as to how much prepared porridge the child had consumed (in $\mathrm{ml}$ ) within each of the $2 \mathrm{~d}$ before the visit and whether consumption on these days was typical. For each month the mean and standard deviation reported intake of the porridge food provided was calculated for 'typical' days. Infants were given adherence scores of 1 (low, $<1$ sD below the mean), 2 (average, \pm 1 sD of the mean) or 3 (high, $>1 \mathrm{sD}$ above the mean). Missed visits were assigned an adherence value of 1 .

\section{Measurements}

At recruitment, sociodemographic information was obtained by questionnaire. Infants had their developmental milestones assessed at the monthly visits to the clinic. Bayley scales of infant development (BSID), anthropometric measurements and $\mathrm{Hb}$ concentration were evaluated at 6, 12 and 18 months of age at the clinic. At 18 months, children were tested for antibodies to HIV using Determine HIV 1/2 (Inverness Medical, Tokyo, Japan) and the results confirmed using Unigold HIV 1/2 (Trinity Biotech plc, Bray, Co. Wicklow, Republic of Ireland).

Development milestones. Data on the attainment of milestones were collected using a test previously developed for Bangladeshi children that included motor milestones taken from the WHO Multicentre Growth Reference Study ${ }^{(21)}$. Mothers were asked at each monthly visit whether and at what age their child had achieved any of the following developmental milestones: (1) motor skills: hands come together, picks up small objects, transfers spoon from hand to hand, sits unsupported, sits supported, crawls, standing with support, standing unsupported, walks supported, walks unsupported; (2) language skills: babbles, says three or four clear words; and (3) social development: smiles when smiled at, shows apprehension at strangers. Children were asked to demonstrate any new milestone reported by the mothers. The milestone was recorded as achieved only after project staff witnessed it.

Mental and psychomotor development evaluation. BSID II were used to assess child development. The test has two subscales: the mental development index (MDI) and psychomotor development index (PDI) and was standardised in the $\mathrm{USA}^{(22)}$. Each index is age-normalised with respect to a population mean of 100 and SD of 15 . The test was administered by two trained psychologists (P. K. K. and H. K. B.). A few of the items were adapted to the different setting (for example, appearance of the dolls or pictures of the houses) but the underlying constructs were unchanged. The test was translated to and back-translated from the local languages (Bemba and Nianja) and administered in the language that was spoken most in the household. If a child was sick on the day of the assessment, the mother was asked to bring the child back 1-2 weeks after recovery.

\section{Data management and statistical methods}

Data were double-entered and verified in Access (Microsoft Corp, Redmond, WA, USA). Range and logical checks were run in Access and in Stata (StataCorp LP, College Station, TX, USA). Stata version 11 was used for all analyses. The analysis plan was finalised before the trial was unblinded.

Numbers of infants missing development evaluations were reported by trial arm. Characteristics of missing infants were examined by logistic regression to verify if there were important differences between infants with complete and incomplete data and to investigate the most plausible missing data mechanism $^{(23)}$.

The number of milestones reached at 12, 15 and 18 months was compared between trial arms using Poisson regression ${ }^{(24)}$. We chose 12- and 18-month time points because the Bayley test was performed at these visits. However, since early results indicated that $>90 \%$ of children had reached most of the milestones at 18 months, we included also an evaluation at 15 months. The mean age of walking unsupported and speaking three or four clear words were compared between trial arms using Cox regression ${ }^{(24)}$.

Inter-observer reliability of the Bayley test was obtained in 663 testing sessions in which the same child was scored by the two psychologists. The intra-class correlation coefficient (ICC) of inter-rater data was calculated using one-way ANOVA. A good agreement between assessors was found for both MDI (ICC $=0.91 ; 95 \%$ CI $0.89, \quad 0.92)$ and PDI (ICC $=0.91 ; 95 \%$ CI 0.90, 0.92). Associations of Bayley test scores at 6 and 18 months with characteristics of the participants and their socio-economic background were examined by linear regression. At 18 months, the analysis was adjusted for treatment arm.

MDI and PDI scores were analysed as continuous variables and checked for normality by normal probability plot. The comparison of MDI and PDI scores at 12 and 18 months between trial arms was made with multivariable linear regression with subsequent adjustment for baseline scores, imbalances at baseline and possible confounding factors. A two-sided $P \leq 0.05$ was considered statistically significant. Maternal education, language spoken and socio-economic status (SES) were considered a priori confounders and were adjusted for in the analyses. SES was measured using an asset index, created by combining data on possessions and housing characteristics using principal component analysis ${ }^{(25)}$. Stunting was considered as length/age $Z$ score $<-2$, calculated using the WHO growth reference data ${ }^{(26)}$ and the child's exact age at measurement. Anaemia was defined as $\mathrm{Hb}$ level $<105 \mathrm{~g} / \mathrm{l}$. Although Bayley MDI and PDI scores were already age standardised, we included age at the assessment in the multivariate model because their standardisation is based on data from the USA and it may not be sufficient to control for the confounding effect of age in this population.

To explore the effects of trial intervention on MDI and PDI scores over the entire follow-up period, alternative 
mixed-effects linear regression models were fitted ${ }^{(27)}$. A random-intercept and random-slope model was found to best account for the between-child variation in the trajectories. Baseline scores, imbalances at baseline and a priori confounding factors were also included. In addition, since a random-effect model leads to unbiased estimates even in the presence of missing values in the outcome variables (i.e. infants lost to follow up or missing the intermediate visit) under the missing at random assumption, we included in the model the covariates that were found to be associated with missingness ${ }^{(23)}$. Time-treatment interaction and interactions between treatment and sex, maternal HIV, breast-feeding and anaemia at baseline were explored as programmed in the analysis plan.

\section{Sample size}

The sample size calculations were done considering the primary outcome - stunting - of the trial ${ }^{(15)}$. Developmental milestones were collected in all the infants in the CIGNIS trial.

For the Bayley test, we hypothesised a treatment effect of $0.3 \mathrm{SD}$ or five points on the MDI and PDI, based on previous studies of the effect of nutritional supplementation on mental and motor development ${ }^{(28)}$. Because the full sample size of the trial was not needed to detect this difference with $90 \%$ power and $5 \%$ level of significance, only a subsample of children was assessed with the Bayley scales. Bayley testing was done in a subsample ( $n$ 502) that included all the children of HIV-positive or HIV-unknown mothers and every other child of HIV-negative women. In addition, this subsample received an intestinal permeability test, another secondary objective of the trial that is not reported here.

\section{Ethics}

The study was conducted according to the Declaration of Helsinki and Good Clinical Practice. The ethics committees of the University of Zambia and the London School of Hygiene and Tropical Medicine approved it. Mothers gave written informed consent. Neither funding source (the Bill and Melinda Gates Foundation and DSM South Africa) was involved in conduct, analysis or interpretation of the study.

\section{Results}

\section{Developmental milestones}

Developmental milestones were recorded for 740 children of the 743 participating in the CIGNIS study (data were not collected for three infants who left the study after a few weeks).

As already described in the analysis of the main trial outcome $e^{(15)}$, there was a $23 \%$ loss to follow-up in both trial arms before the infants reached 18 months (Supplemental Fig. 1; available online at http://www.journals.cambridge. org/bjn). There were more infants of HIV-uninfected women (77\%) among those lost to follow-up than among those who completed the study (68\%) but these groups were otherwise similar $^{(15)}$.

The amount of porridge consumed increased with age from about $268 \mathrm{ml} / \mathrm{d}$ (about $32 \mathrm{~g}$ flour/d) at 7 months to about $369 \mathrm{ml} / \mathrm{d}$ (about $44 \mathrm{~g}$ flour$/ \mathrm{d}$ ) from 11 to 18 months. There was no evidence that adherence differed between treatment groups (OR and 95\% CI for proportion of visits with high adherence in the richly fortified compared with the basal diet: OR 0.79; 95\% CI 0.61, 1.04).

At baseline, the trial arms were substantially balanced (Supplemental Table 1; available online at http://www. journals.cambridge.org/bjn) ${ }^{(15)}$ and not different in terms of number of milestones reached (Table 2). At 12, 15 and 18 months the number of milestones attained did not differ between trial arms. As expected, none of the children was able to walk unsupported or speak three or four clear words at 6 months. Age of achieving the two above milestones was similar between trial arms (Fig. 1). These results did not change after adjusting for the sex of the child and education and SES of the mother. There was no evidence of interactions between treatment and child's sex, anaemia at baseline, breast-feeding and maternal HIV status (data not shown).

\section{Bayley test}

Among the 743 infants enrolled in the CIGNIS trial and randomised, a subsample of 502 was assigned to Bayley testing according to the study design; of those, 256 (51\%) were in the basal fortified porridge group and 246 (49\%) in the richly fortified porridge group (Fig. 2).

Table 2. Developmental milestones achieved by four consecutive time points by trial arm (Medians and interquartile ranges (IQR) and rate ratios (RR) and $95 \%$ confidence intervals)

\begin{tabular}{|c|c|c|c|c|c|c|c|c|c|c|c|}
\hline \multirow[b]{3}{*}{ Age } & \multirow[b]{3}{*}{$n$} & \multicolumn{4}{|c|}{ No. of milestones achieved } & & & & & & \\
\hline & & \multicolumn{2}{|c|}{$\begin{array}{l}\text { Basal fortified } \\
\text { porridge }(n 370)\end{array}$} & \multicolumn{2}{|c|}{$\begin{array}{l}\text { Richly fortified } \\
\text { porridge ( } n 370)\end{array}$} & \multicolumn{3}{|c|}{ Unadjusted* } & \multicolumn{3}{|c|}{ Adjusted $†$} \\
\hline & & Median & IQR & Median & IQR & $\mathrm{RR}$ & $95 \% \mathrm{Cl}$ & $P$ & $\mathrm{RR}$ & $95 \% \mathrm{Cl}$ & $P$ \\
\hline 6 months & 740 & 8 & $7-9$ & 8 & $7-9$ & 1.00 & $0.95,1.06$ & 0.90 & - & - & - \\
\hline 12 months & 619 & 13 & $12-13$ & 13 & $12-13$ & 1.00 & $0.96,1.05$ & 0.91 & 1.00 & $0.96,1.05$ & 0.88 \\
\hline 15 months & 583 & 14 & $13-14$ & 14 & $13-14$ & 1.00 & $0.96,1.05$ & 0.76 & 1.00 & $0.96,1.05$ & 0.77 \\
\hline 18 months & 576 & 14 & $14-14$ & 14 & $14-14$ & 1.00 & $0.96,1.05$ & 0.92 & 1.00 & $0.96,1.05$ & 0.93 \\
\hline
\end{tabular}

*Basal fortified porridge used as the baseline category.

†Adjusted for sex, socio-economic status and maternal education. 


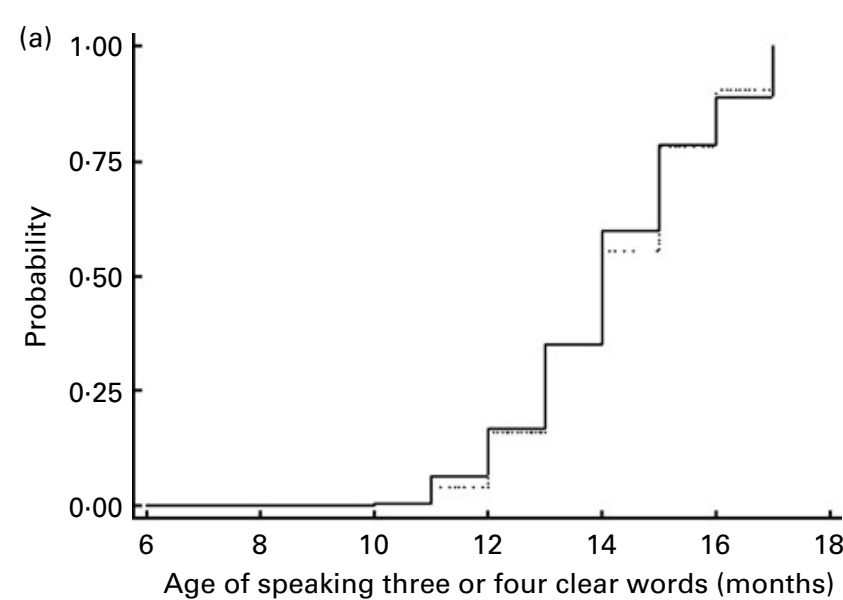

(b)

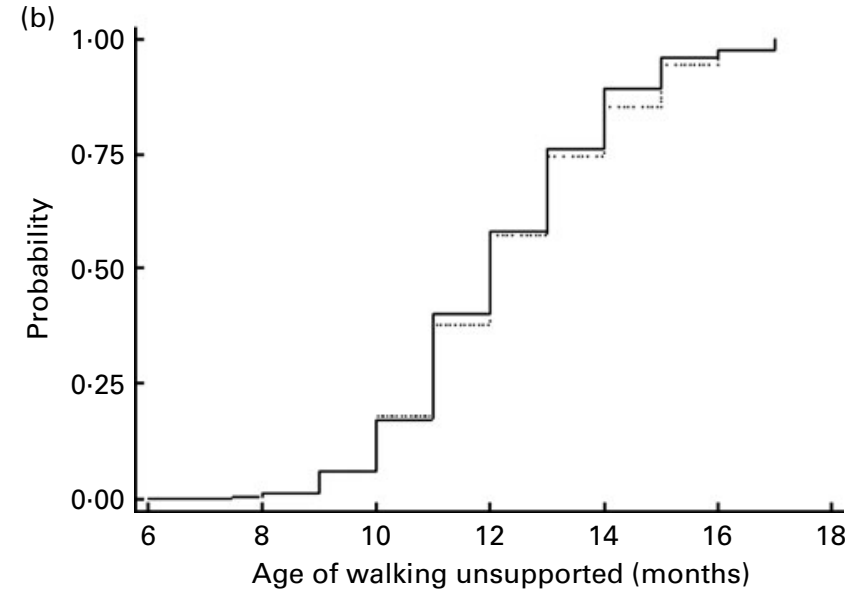

Fig. 1. Age of speaking three or four clear words (a) and of walking unsupported (b) by intervention arm. Probabilities of reaching the milestones were estimated using Kaplan-Meier methods. The hazard ratios (HR) of reaching the milestones for the richly fortified porridge arm $(-)$ compared with the basal fortified porridge arm (.....) are presented as crude HR and adjusted by sex, socio-economic status and maternal education. Age of speaking three or four clear words: crude HR $1.02(95 \% \mathrm{Cl} 0.85,1.21), P=0.84$; adjusted HR $1.01(95 \% \mathrm{Cl} 0.84,1.20), P=0.94$. Age of walking unsupported: crude HR $1.06(95 \% \mathrm{Cl} 0.89,1.26), P=0.49$; adjusted HR $1.04(95 \% \mathrm{Cl} 0.88$, 1.24), $P=0.63$

As planned, all the infants of HIV-positive/unknown mothers and approximately half of the infants of HIV-negative mothers were included in the Bayley test subsample (Table 3, left-hand columns). Baseline characteristics did not differ between infants of HIV-negative mothers assigned and not assigned to Bayley testing

Trial arms were reasonably balanced at baseline (Table 3, right-hand columns), although there was some evidence of an excess of girls $(P<0.04)$ and more mothers with none/ primary education $(P<0.02)$ in the richly fortified arm. At 18 months, 332 of the 335 infants followed up were tested for HIV antibodies and thirteen (4\%) were HIV positive.

Bayley test assessment was affected by missing data at baseline and at follow up. Their frequency and consequences are discussed below.

Loss at baseline: thirty-nine infants in the richly fortified porridge group and forty-three in the basal fortified group, who were assigned to Bayley testing according to the study design, were not assessed at baseline (Fig. 2). The main reason was the mother's refusal to spend the time to receive the full protocol including the Bayley test and gut permeability test. A total of five infants did not receive the full protocol because trial staff incorrectly gave them the reduced protocol. An incorrect HIV status was reported by four mothers, which was subsequently ascertained by checking clinical charts; this influenced the assignment of their infants to the full protocol. Also, ten infants did not receive the Bayley test because the solution for gut permeability was not available and they were assigned to the reduced protocol. As a result, among those 502 planned to receive Bayley testing, only 420 (84\%) were assessed at baseline (Fig. 2). The infants who missed Bayley assessment did not substantially differ from those who received Bayley testing in baseline characteristics, growth and developmental milestones achieved (data not shown) except that the proportion of HIV-negative mothers was significantly higher in the group missing the Bayley test (94 v. $48 \% ; P<0 \cdot 01$ ).

Loss to follow-up: among 420 infants assessed at baseline with the Bayley test, eighty-five (20\%) were lost between 6 and 18 months, with no evidence of a difference between treatment arms (18\% in basal and $23 \%$ in micronutrientfortified arm; $P=0 \cdot 22$ ). Baseline characteristics were similar between these infants and those who completed the study (data not shown), except that mothers lost to follow up were younger (mean age 24.7 (SD 6.0) v. $27 \cdot 2$ (SD 5.9) years; $P<0.01$ ), and the proportion that was HIV negative was slightly higher (54 v. 46\%; $P=0.07$ ). MDI and PDI scores at baseline and before withdrawal were not significantly different in those lost to follow up compared with children who completed (data not shown).

The available Bayley testing measures obtained on these children were first studied in relation to the children and their mothers' baseline characteristics, and then in relation to the assigned intervention as follows.

At baseline, both MDI and PDI were significantly associated $(P<0.01)$ with birth weight and concurrent stunting (Table 4). Infants who were anaemic had on average lower MDI and PDI scores compared with non-anaemic ones, but the difference was statistically significant $(P=0 \cdot 01)$ only for MDI. At 18 months, there was still evidence of an association of both MDI and PDI scores with concurrent stunting $(P<0 \cdot 01)$. Infants born with low birth weight had lower scores also at 18 months, but the difference was statistically significant only for PDI $(P<0 \cdot 01)$. PDI was also associated with maternal education, SES and language. In infants of HIV-positive mothers, there was some evidence of poorer MDI and PDI scores at 18 months compared with infants of HIV-negative or HIV-unknown mothers $(P=0.03)$. MDI and PDI scores were lower in those thirteen infants who were found to be HIV infected at 18 months, but the difference was not statistically significant.

Both MDI and PDI decreased from 6 to 18 months similarly in both treatment arms (Table 5). Significant differences between treatment arms were seen only for PDI at 18 months $(P=0.03)$; infants in the richly fortified arm scored on average 1.6 points lower than those in the basal fortified arm (Table 5). This result did not substantially change after 


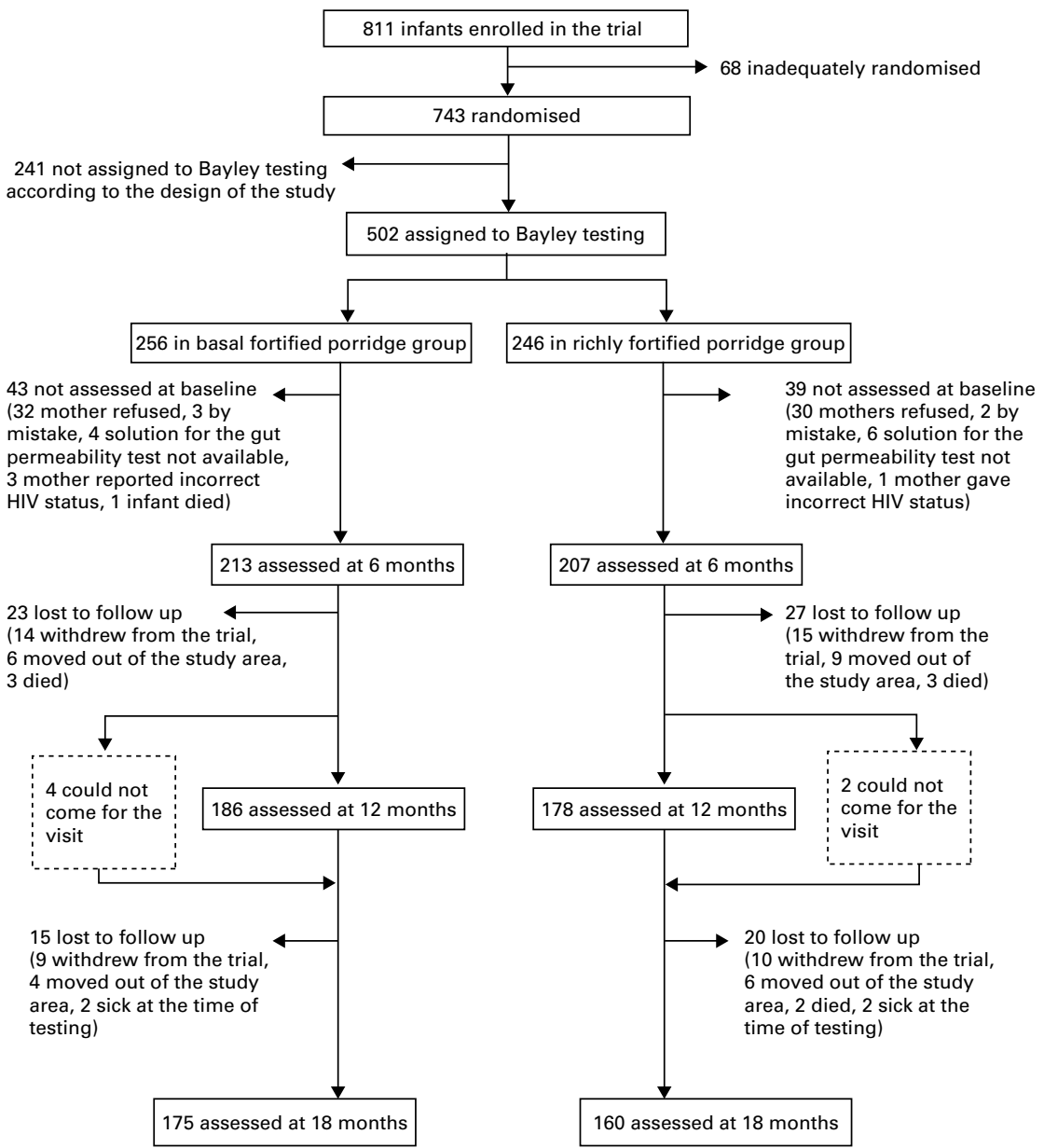

Fig. 2. Flow diagram displaying infants recruited in the Bayley test subsample and lost to follow up by treatment arm.

adjusting for baseline scores, imbalances at baseline between trial arms (sex and maternal education) and a priori confounding factors (age at the assessment, maternal language and SES). However, these results could be affected by losses to follow up.

Results from the mixed-effects linear regression models showed that, after adjusting for baseline scores, imbalances at baseline, a priori confounding factors and characteristics associated with missingness (mother's age and HIV status), there was no evidence that the children in the richly fortified porridge arm had, considering the overall study period, different MDI and PDI scores compared with the basal fortified porridge arm (difference in MDI scores: 0.3 (95\% CI - 0.5, 1.1), $P=0.43$; difference in PDI scores: -0.1 (95\% CI -0.9 , $0 \cdot 7), P=0 \cdot 78)$. There was no evidence of interactions between treatment and follow-up time, infant's sex and anaemia at baseline, maternal HIV status and breast-feeding (data not shown).

\section{Discussion}

In the CIGNIS trial, provision from ages 6 to 18 months of a micronutrient-richly fortified porridge, formulated to meet all nutritional requirements according to current best estimates $^{(19)}$, did not show any clear benefit on mental and psychomotor development evaluated with developmental milestones and BSID II. There was evidence from mothers' report that the children took the supplement and there was a good response in $\mathrm{Hb}$ levels ${ }^{(15)}$. The only significant difference seen was that PDI scores at 18 months were lower in the richly fortified porridge arm compared with the control arm, which is the opposite to our hypothesis that multiple micronutrients would benefit child development. However, the difference was very small (1.6 points) and was below that one generally considered clinically relevant ${ }^{(28)}$. Moreover, the longitudinal analysis, which corrects for incomplete information due to missing data, indicated no evidence of an intervention effect on MDI or PDI on the overall study period.

The infants' Bayley scores were in the normal range at baseline but decreased with age, while achievement of motor and language milestones reflected the standards for healthy children up to 15 months of age ${ }^{(29,30)}$. Most children attained all milestones before 18 months, so no milestone was available to measure developmental level in the older age range. The decline in Bayley scores with age in these Zambian children is consistent with findings in other resource-poor settings ${ }^{(6,10,11,31-34)}$. The decrease could be attributed to cumulative developmental delay due to disadvantaged backgrounds compared with US standards. 
Table 3. Baseline characteristics of children assigned ( $n$ 502) and not assigned ( $n$ 241) to Bayley testing, and of those assigned to Bayley testing by intervention arm

(Numbers in groups and percentages or mean values and standard deviations)

\begin{tabular}{|c|c|c|c|c|c|c|c|c|c|c|}
\hline & \multicolumn{6}{|c|}{$\begin{array}{l}\text { Children assigned ( } n \text { 502) and not assigned ( } n 241) \text { to Bayley testing } \\
\text { by HIV status }\end{array}$} & \multicolumn{4}{|c|}{$\begin{array}{l}\text { Children assigned to Bayley testing } \\
\text { by intervention arm }\end{array}$} \\
\hline & \multicolumn{2}{|c|}{$\begin{array}{c}\text { Mother HIV } \\
\text { positive }(n 157) \text { or } \\
\text { unknown }(n 67)^{*}\end{array}$} & \multicolumn{2}{|c|}{$\begin{array}{l}\text { Mother HIV negative } \\
\text { assigned }(n \text { 278) }\end{array}$} & \multicolumn{2}{|c|}{$\begin{array}{c}\text { Mother HIV } \\
\text { negative not } \\
\text { assigned ( } n \text { 241) }\end{array}$} & \multicolumn{2}{|c|}{$\begin{array}{l}\text { Basal fortified } \\
\text { porridge }(n 256)\end{array}$} & \multicolumn{2}{|c|}{$\begin{array}{l}\text { Richly fortified } \\
\text { porridge }(n 246)\end{array}$} \\
\hline & $n$ & $\%$ & $n$ & $\%$ & $n$ & $\%$ & $n$ & $\%$ & $n$ & $\%$ \\
\hline \multicolumn{11}{|l|}{ Infants' characteristics } \\
\hline \multicolumn{11}{|l|}{ Age (months) } \\
\hline Mean & \multirow{2}{*}{\multicolumn{2}{|c|}{$\begin{array}{l}6.1 \\
0.3\end{array}$}} & \multirow{2}{*}{\multicolumn{2}{|c|}{$\begin{array}{l}6 \cdot 1 \\
0.3\end{array}$}} & \multirow{2}{*}{\multicolumn{2}{|c|}{$\begin{array}{l}6 \cdot 0 \\
0.3\end{array}$}} & \multicolumn{2}{|c|}{$6 \cdot 1$} & \multicolumn{2}{|c|}{$6 \cdot 0$} \\
\hline SD & & & & & & & \multicolumn{2}{|c|}{0.3} & \multicolumn{2}{|c|}{0.3} \\
\hline Sex, male & 99 & 44.2 & 137 & $49 \cdot 3$ & 121 & $50 \cdot 2$ & 132 & $51 \cdot 6$ & 104 & $42 \cdot 3$ \\
\hline Low birth weight, $<2.5 \mathrm{~kg} \dagger$ & 29 & $13 \cdot 2$ & 36 & $13 \cdot 1$ & 34 & $14 \cdot 2$ & 35 & $14 \cdot 0$ & 30 & $12 \cdot 4$ \\
\hline Stunted at 6 months $\ddagger$ & 33 & $14 \cdot 8$ & 28 & $10 \cdot 1$ & 30 & $12 \cdot 5$ & 34 & $13 \cdot 3$ & 27 & 11.0 \\
\hline \multicolumn{11}{|l|}{ Breast feeding } \\
\hline Never breastfed & 40 & $17 \cdot 9$ & 2 & 0.7 & 1 & 0.4 & 22 & $8 \cdot 6$ & 20 & $8 \cdot 1$ \\
\hline$<6$ months & 52 & $23 \cdot 2$ & 10 & 3.6 & 6 & 2.5 & 34 & $13 \cdot 3$ & 28 & 11.4 \\
\hline$\geq 6$ months & 132 & 58.9 & 265 & 95.7 & 235 & $97 \cdot 1$ & 200 & $78 \cdot 1$ & 198 & 80.5 \\
\hline Anaemia, $\mathrm{Hb}<105 \mathrm{~g} / \mathrm{l} \S$ & 91 & 41.5 & 105 & 38.0 & 93 & $39 \cdot 6$ & 94 & $36 \cdot 9$ & 102 & $42 \cdot 5$ \\
\hline \multicolumn{11}{|l|}{ Mothers' characteristics } \\
\hline \multicolumn{11}{|l|}{ Age (years) } \\
\hline Mean & \multirow{2}{*}{\multicolumn{2}{|c|}{$\begin{array}{c}27.7 \\
5.6\end{array}$}} & \multirow{2}{*}{\multicolumn{2}{|c|}{$\begin{array}{c}25.4 \\
5.7\end{array}$}} & \multirow{2}{*}{\multicolumn{2}{|c|}{$\begin{array}{c}25.7 \\
5.7\end{array}$}} & \multicolumn{2}{|c|}{$26 \cdot 4$} & \multicolumn{2}{|c|}{$26 \cdot 5$} \\
\hline SD & & & & & & & & & & \\
\hline HIV status & & & & & & & & & & \\
\hline Negative & - & - & - & - & - & - & 144 & $56 \cdot 3$ & 134 & 54.5 \\
\hline Positive & - & - & - & - & - & - & 79 & $31 \cdot 1$ & 78 & $31 \cdot 6$ \\
\hline Unknown & - & - & - & - & - & - & 33 & $13 \cdot 0$ & 34 & $13 \cdot 8$ \\
\hline Education & & & & & & & & & & \\
\hline None/primary & 87 & $38 \cdot 8$ & 91 & $32 \cdot 7$ & 74 & $30 \cdot 7$ & 80 & $31 \cdot 2$ & 98 & 39.8 \\
\hline Secondary & 88 & $39 \cdot 3$ & 102 & $36 \cdot 7$ & 95 & $39 \cdot 0$ & 112 & $43 \cdot 8$ & 78 & 31.7 \\
\hline College/university & 49 & 21.9 & 85 & $30 \cdot 6$ & 73 & $30 \cdot 3$ & 64 & $25 \cdot 0$ & 70 & 28.5 \\
\hline Marital status & & & & & & & & & & \\
\hline Married & 169 & $75 \cdot 5$ & 205 & 73.7 & 183 & $75 \cdot 9$ & 191 & 74.6 & 183 & 74.4 \\
\hline Single or never married & 41 & $18 \cdot 3$ & 59 & $21 \cdot 2$ & 51 & $21 \cdot 2$ & 54 & $21 \cdot 1$ & 46 & $18 \cdot 7$ \\
\hline Widowed/divorced & 14 & $6 \cdot 2$ & 14 & $5 \cdot 1$ & 7 & 2.9 & 11 & 4.3 & 17 & $6 \cdot 9$ \\
\hline Socio-economic status & & & & & & & & & & \\
\hline Low & 84 & 37.5 & 87 & $31 \cdot 3$ & 79 & $32 \cdot 8$ & 84 & $32 \cdot 8$ & 87 & 35.4 \\
\hline Middle & 83 & $37 \cdot 1$ & 108 & $38 \cdot 8$ & 96 & 39.8 & 107 & $41 \cdot 8$ & 84 & $34 \cdot 1$ \\
\hline High & 57 & $25 \cdot 4$ & 83 & 29.9 & 66 & $27 \cdot 4$ & 65 & $25 \cdot 4$ & 75 & 30.5 \\
\hline Language English & 94 & $42 \cdot 7$ & 110 & 54.7 & & & 102 & $47 \cdot 7$ & 102 & $49 \cdot 3$ \\
\hline
\end{tabular}

*All planned to have Bayley testing.

†Information was missing for eleven children.

$\ddagger$ Length for age $<-2 Z$; not available for one child.

§Information was missing for thirteen children.

|| Data not collected for children not assigned to Bayley testing.

Although some of the families were classified as middle/high class, approximately $23 \%$ of children were stunted by the end of the study and about one-third of the mothers had primary education only. Unfortunately, we had no measure of stimulation in the home, an important determinant of child development. Zambian infants had lower variability of scores compared with the reference US population ${ }^{(35)}$. This is probably explained by the fact that the US reference population included a representative sample of all socio-economic and ethnic groups and geographical regions, whereas the CIGNIS infants were from one urban area and were ethnically, socio-economically and culturally more homogeneous.

There are no standardised infant tests available for Zambia. However, one or both Bayley scores at baseline were related to low birth weight, stunting and anaemia in the expected direction $^{(2,36)}$. Furthermore, at 18 months when the effect of environment is generally more apparent, the Bayley scores were also related to mothers' HIV status and educational level, the language spoken at home and SES, all in the expected direction. Inter-observer reliability was good, so the scores appear to be valid for Zambian children. Furthermore, the Bayley scales have been used to assess infant development in many studies in low- and middle-income countries $^{(6,10,31-34)}$. Since the study began, a new tool to assess child development milestones in rural African settings has been developed and validated in Malawian children ${ }^{(37)}$. A posteriori comparison is difficult because the test was designed specifically for a rural environment, while our infants are from an urban setting. However, age of walking unsupported and speaking three or four clear words in our infants are compatible with the normal range in those Malawian infants ${ }^{(37)}$. 
Table 4. Univariable association between mental development index (MDI) and psychomotor development index (PDI) scores at 6 and 18 months and characteristics of the infants and their mothers (Mean values and standard deviations)

\begin{tabular}{|c|c|c|c|c|c|c|c|c|c|c|c|c|c|c|c|c|}
\hline & \multicolumn{8}{|c|}{6 months } & \multicolumn{8}{|c|}{18 months } \\
\hline & \multicolumn{2}{|c|}{ Subjects ( $n$ 420) } & \multicolumn{3}{|c|}{ MDI score } & \multicolumn{3}{|c|}{ PDI score } & \multicolumn{2}{|c|}{ Subjects ( $n$ 335) } & \multicolumn{3}{|c|}{ MDI score } & \multicolumn{3}{|c|}{ PDI score } \\
\hline & $n$ & $\%$ & Mean & SD & $P$ & Mean & SD & $P$ & $n$ & $\%$ & Mean & SD & $P^{*}$ & Mean & SD & $P^{*}$ \\
\hline \multicolumn{17}{|l|}{ Infants' characteristics } \\
\hline \multicolumn{17}{|l|}{ Sex } \\
\hline Male & 199 & $47 \cdot 4$ & 99.2 & $7 \cdot 0$ & & $102 \cdot 1$ & $10 \cdot 0$ & & 159 & 47.5 & 88.4 & 7.9 & & 90.5 & 6.5 & \\
\hline Female & 221 & $52 \cdot 6$ & $99 \cdot 0$ & 6.9 & 0.83 & $102 \cdot 3$ & $9 \cdot 3$ & 0.82 & 176 & 52.5 & $89 \cdot 6$ & $6 \cdot 8$ & $0 \cdot 19$ & 90.9 & $5 \cdot 8$ & 0.39 \\
\hline \multicolumn{17}{|l|}{ Birth weight $†$} \\
\hline$<2.5 \mathrm{~kg}$ & 54 & $13 \cdot 1$ & $95 \cdot 3$ & $10 \cdot 6$ & & 96.9 & 14.4 & & 45 & $13 \cdot 6$ & $87 \cdot 2$ & 7.4 & & $88 \cdot 3$ & $6 \cdot 0$ & \\
\hline$\geq 2.5 \mathrm{~kg}$ & 358 & $86 \cdot 9$ & $99 \cdot 7$ & $6 \cdot 0$ & $<0.01$ & $103 \cdot 1$ & $8 \cdot 3$ & $<0.01$ & 287 & $86 \cdot 4$ & $89 \cdot 3$ & 7.4 & 0.09 & $91 \cdot 1$ & $6 \cdot 1$ & $<0.01$ \\
\hline \multicolumn{17}{|c|}{ Stunting at the assessment $\neq$} \\
\hline Yes & 55 & $13 \cdot 1$ & $95 \cdot 7$ & $9 \cdot 3$ & & $97 \cdot 2$ & $13 \cdot 6$ & & 77 & $23 \cdot 1$ & $86 \cdot 0$ & $7 \cdot 6$ & & $87 \cdot 3$ & $8 \cdot 0$ & \\
\hline No & 364 & $86 \cdot 9$ & 99.6 & 6.4 & $<0.01$ & $103 \cdot 0$ & 8.5 & $<0.01$ & 257 & $76 \cdot 9$ & 89.9 & $7 \cdot 1$ & $<0.01$ & $91 \cdot 7$ & $5 \cdot 1$ & $<0.01$ \\
\hline \multicolumn{17}{|c|}{ Anaemia at the assessment§ } \\
\hline Yes & 163 & 39.4 & $98 \cdot 1$ & $7 \cdot 1$ & & 101.4 & $10 \cdot 1$ & & 104 & $31 \cdot 3$ & 87.9 & $6 \cdot 7$ & & $90 \cdot 0$ & $6 \cdot 0$ & \\
\hline No & 251 & $60 \cdot 6$ & 99.8 & $6 \cdot 8$ & 0.01 & $102 \cdot 7$ & 9.2 & 0.20 & 228 & 68.7 & 89.5 & $7 \cdot 6$ & $0 \cdot 11$ & $90 \cdot 9$ & $6 \cdot 2$ & 0.07 \\
\hline \multicolumn{17}{|c|}{ HIV status at 18 months\| } \\
\hline Negative & & & & & & & & & 319 & $96 \cdot 1$ & 89.1 & $7 \cdot 4$ & & $90 \cdot 8$ & $6 \cdot 2$ & \\
\hline Positive & & & & & & & & & 13 & 3.9 & $87 \cdot 3$ & $9 \cdot 0$ & 0.37 & 88.5 & 6.5 & 0.20 \\
\hline \multirow{2}{*}{\multicolumn{17}{|c|}{ Mothers' characteristics }} \\
\hline & & & & & & & & & & & & & & & & \\
\hline Negative & 201 & $47 \cdot 9$ & $99 \cdot 3$ & $6 \cdot 4$ & & $102 \cdot 4$ & $9 \cdot 1$ & & 155 & $46 \cdot 3$ & 89.4 & $6 \cdot 8$ & & 91.4 & 5.5 & \\
\hline Positive & 156 & $37 \cdot 1$ & 98.9 & 7.4 & & 101.9 & $10 \cdot 1$ & & 133 & 39.7 & 87.9 & 7.6 & & $89 \cdot 6$ & $7 \cdot 1$ & \\
\hline Unknown & 63 & $15 \cdot 0$ & $98 \cdot 7$ & 7.5 & 0.78 & $102 \cdot 1$ & $10 \cdot 0$ & 0.85 & 47 & $14 \cdot 0$ & 91.0 & 8.2 & 0.03 & 91.6 & $4 \cdot 8$ & 0.03 \\
\hline \multicolumn{17}{|l|}{ Education } \\
\hline None/primary & 149 & 35.5 & $98 \cdot 8$ & $7 \cdot 4$ & & $102 \cdot 3$ & $10 \cdot 6$ & & 112 & 33.4 & 88.9 & 7.3 & & $89 \cdot 2$ & $7 \cdot 1$ & \\
\hline Secondary & 164 & $39 \cdot 0$ & $99 \cdot 3$ & $6 \cdot 7$ & & $102 \cdot 7$ & 8.9 & & 134 & $40 \cdot 0$ & 88.5 & 7.5 & & 91.2 & $5 \cdot 8$ & \\
\hline College/university & 107 & $25 \cdot 5$ & $99 \cdot 1$ & $6 \cdot 6$ & 0.78 & $101 \cdot 2$ & $9 \cdot 3$ & 0.47 & 89 & $26 \cdot 6$ & $89 \cdot 8$ & 7.5 & 0.51 & $91 \cdot 8$ & $5 \cdot 1$ & 0.02 \\
\hline \multicolumn{17}{|l|}{ Socio-economic status } \\
\hline Low & 152 & $36 \cdot 2$ & $98 \cdot 8$ & $7 \cdot 7$ & & $102 \cdot 9$ & $10 \cdot 7$ & & 117 & 34.9 & 88.5 & $6 \cdot 6$ & & $89 \cdot 6$ & $6 \cdot 2$ & \\
\hline Middle & 158 & $37 \cdot 6$ & $99 \cdot 2$ & $6 \cdot 4$ & & 101.4 & $9 \cdot 0$ & & 128 & 38.2 & $89 \cdot 0$ & $8 \cdot 1$ & & $91 \cdot 0$ & 6.5 & \\
\hline High & 110 & $26 \cdot 2$ & $99 \cdot 3$ & 6.5 & 0.76 & $102 \cdot 2$ & 8.8 & 0.38 & 90 & $26 \cdot 9$ & 89.6 & $7 \cdot 2$ & 0.53 & $91 \cdot 7$ & 5.5 & 0.05 \\
\hline \multicolumn{17}{|l|}{ Language } \\
\hline English & 203 & $48 \cdot 3$ & 99.2 & $6 \cdot 2$ & & $102 \cdot 1$ & $8 \cdot 8$ & & 164 & $49 \cdot 0$ & 89.0 & 7.4 & & 91.7 & $5 \cdot 0$ & \\
\hline Other languages ${ }^{\star *}$ & 217 & $51 \cdot 7$ & $99 \cdot 0$ & $7 \cdot 7$ & 0.69 & $102 \cdot 2$ & $10 \cdot 3$ & 0.90 & 171 & $51 \cdot 0$ & $89 \cdot 0$ & 7.5 & 0.92 & 89.7 & $7 \cdot 0$ & $<0.01$ \\
\hline
\end{tabular}

* $P$ value at 18 months obtained by linear regression adjusting for treatment arm.

† Information was missing for eight infants.

¥Length for age $<-2 Z$; not available for one infant.

$\S \mathrm{Hb}<105 \mathrm{~g} /$; information was missing for seven infants at 6 months and three infants at 18 months.

NNot available for three infants.

I Reported or from clinical records.

${ }^{* *}$ Bemba or Nyanja. 
Table 5. Mental development index (MDI) and psychomotor development index (PDI) scores at 6, 12 and 18 months

(Mean values and standard deviations and differences and $95 \%$ confidence intervals)

\begin{tabular}{|c|c|c|c|c|c|c|c|c|c|c|}
\hline & \multicolumn{2}{|c|}{$\begin{array}{l}\text { Basal fortified } \\
\text { porridge }(n 256)\end{array}$} & \multicolumn{2}{|c|}{$\begin{array}{l}\text { Richly fortified } \\
\text { porridge }(n 246)\end{array}$} & \multicolumn{3}{|c|}{ Unadjusted ${ }^{\star}$} & \multicolumn{3}{|c|}{ Adjusted $^{*} \dagger$} \\
\hline & Mean & SD & Mean & SD & Difference & $95 \% \mathrm{Cl}$ & $P$ & Difference & $95 \% \mathrm{Cl}$ & $P$ \\
\hline \multicolumn{11}{|c|}{6 months ( $n$ 420) } \\
\hline MDI score & 99.0 & $6 \cdot 4$ & 99.2 & 7.5 & 0.1 & $-1 \cdot 2,1.5$ & 0.84 & - & - & - \\
\hline PDI score & $102 \cdot 0$ & 9.0 & $102 \cdot 3$ & $10 \cdot 3$ & 0.3 & $-1 \cdot 6,2 \cdot 1$ & 0.76 & - & - & - \\
\hline \multicolumn{11}{|c|}{12 months ( $n 364)$} \\
\hline MDI score & 95.1 & $7 \cdot 9$ & $95 \cdot 9$ & $8 \cdot 7$ & 0.8 & $-0.9,2.6$ & 0.33 & 0.8 & $-0.8,2.4$ & 0.34 \\
\hline PDI score & 93.1 & 9.2 & 93.4 & $10 \cdot 4$ & 0.3 & $-1 \cdot 7,2 \cdot 3$ & 0.78 & 0.3 & $-1.5,2 \cdot 1$ & 0.70 \\
\hline \multicolumn{11}{|c|}{18 months $(n 335)$} \\
\hline MDI score & 88.4 & 7.4 & 89.8 & $7 \cdot 4$ & 1.4 & $-0.2,3.0$ & 0.09 & 1.3 & $-0.3,2 \cdot 8$ & 0.11 \\
\hline PDI score & 91.4 & $6 \cdot 1$ & $90 \cdot 0$ & $6 \cdot 2$ & -1.4 & $-2 \cdot 8,-0.1$ & 0.03 & -1.6 & $-2 \cdot 8,-0.3$ & 0.02 \\
\hline
\end{tabular}

*Basal fortified porridge used as the baseline category.

† Adjusted for baseline score, age at the assessment, sex, socio-economic status, maternal education and language (English $v$. other languages).

The present results concur with findings from studies in $\mathrm{Nepal}^{(9)}$, India ${ }^{(10)}$ and Indonesia ${ }^{(11)}$ that found no significant benefit $^{(9,10)}$ or a hint of disadvantage ${ }^{(11)}$ to scores on BSID II. By contrast the present results do not concur with findings from four other studies that found benefits to motor milestones or motor development on the Bayley scales ${ }^{(5-8)}$. In Zanzibar, benefits were found to the age of walking in infants after 1-year supplementation with $\mathrm{Fe}, \mathrm{Zn}$ and folate ${ }^{(8)}$. The effect of intervention was stronger in anaemic children and they had a higher prevalence of anaemia at baseline $(63 \%$ with a cut-off of $100 \mathrm{~g} / \mathrm{l})^{(8)}$ compared with infants in the CIGNIS (approximately $40 \%$ with a cut-off of $105 \mathrm{~g} / \mathrm{l}$ ). However, in the present study, the effect of the intervention was not more beneficial in children anaemic at baseline. In Ghana a positive effect was found on walking at 12 months in the two groups receiving different amounts of micronutrients and one group receiving micronutrients and energy compared with a non-intervention control group ${ }^{(5)}$. However, in that study the control group was not randomised as part of the trial and may not have received the same level of care as the study participants.

The present study has several strengths. It is one of the few randomised controlled trials investigating the effect of multiple micronutrient fortification alone (the two trial porridges had equal amount of energy) on mental and motor development in children under the age of 5 years $^{(4,9)}$ and it was powered to detect clinically significant differences. It was conducted in an area of documented micronutrient malnutrition ${ }^{(12,13)}$ and we had evidence of good compliance ${ }^{(15)}$. The development assessment was comprehensive and the Bayley test showed good reliability and appeared valid in this population.

The study also has some limitations that should be considered when interpreting the results. Bayley assessment was performed in a subsample of the CIGNIS trial, which included all infants of HIV-positive or HIV-unknown mothers and every other child of HIV-negative women. The latter criterion was chosen to spread the testing over the entire study period, thus maintaining a steady workload and the random allocation of intervention. As planned, there was a higher proportion of infants of HIV-positive mothers in the subsample compared with the general population attending the Chilenje clinic.
However, there was no evidence that the effect of the intervention on Bayley scores was modified by maternal HIV status; therefore the present results should be applicable to the general population of Chilenje.

Loss from the study could have biased the results. A number of infants assigned to the Bayley test (16\%) were not tested (mainly because mothers refused) and we had approximately $20 \%$ lost to follow up. Mothers not participating in Bayley testing were more frequently HIV negative, but their infants were otherwise very similar to the Bayley test participants (also in term of growth and milestones achieved) and equally balanced between trial arms. Infants of younger and HIVnegative mothers were more likely to be lost to follow up but were equally balanced between trial arms and their developmental scores at baseline and before withdrawal were similar to those children who completed the follow up. In the analysis, we accounted for losses to follow up, fitting a multilevel mixed-effect model, which has the advantage of implicitly predicting missing values using the overall pattern of the existing data, based on the missing at random assumption $^{(23)}$. In the present study, being lost to follow up was influenced by maternal age and HIV status but was unrelated to the intervention and to outcome measurements before withdrawals, therefore was plausibly at random ${ }^{(23)}$.

As an additional approach to account for both infants not participating in Bayley testing and infants lost to follow up, we imputed missing data using multiple imputations (with ten imputing sets). All the known covariates including those associated with the missingness mechanism (time since enrolment, maternal age and HIV status) and with the outcome measures (growth data) were included in the imputation procedures $^{(23)}$. The results of the analysis with multiple imputations showed no difference between trial arms in term of Bayley scores and milestones achieved (data not shown).

In conclusion, the present study suggests that 1 year of rich multiple micronutrient fortification does not have any benefit on child development compared with basal fortification. The latter coupled with adequate energy intake remains important for Zambian infants and resources should be used to implement this intervention. 


\section{Acknowledgements}

D. M. conducted the statistical analyses and drafted the paper; P. K. K. and H. K. B. administered the BSID II and collected developmental milestones; J. S. was the clinical officer of the Chilenje Clinic and was responsible for clinical follow up of the trial participants and supervised the developmental tests; S. G.-M. participated in the study design and advised on the training and supervision of the personnel involved in the child development evaluation; K. B. participated to the study design and contributed to data analysis; B. L. De S. gave statistical advice and supervision; S. J. was senior investigator of the trial, was involved in the study design and in the interpretation of the results; S. F. was principal investigator of the CIGNIS study, and participated to the study design and interpretation of the results. All authors plus other senior members of the study team commented on and agreed the final manuscript.

The present study was funded by the Bill and Melinda Gates Foundation with micronutrient premixes prepared and supplied by DSM, South Africa. We are grateful to $\mathrm{Mr}$ Chongo of Quality Commodities, Lusaka, for preparing and storing the flours and to Dr Bilal Iqbal for training the trial staff on the Bayley test. We are particularly grateful to the mothers and children who participated in the study and to all the other members of the CIGNIS study team.

The CIGNIS study team comprises: Principal Investigator: Suzanne Filteau, London School of Hygiene and Tropical Medicine (LSHTM); Zambian Lead Investigator: Lackson Kasonka, University Teaching Hospital (UTH), Lusaka; Senior Investigators: Rosalind Gibson, University of Otago, New Zealand; Ursula A. Gompels, LSHTM; Shabbar Jaffar, LSHTM; Emmanuel Kafwembe, Tropical Diseases Research Centre, Ndola; Mwaka Monze, UTH; Moses Sinkala, Catholic Relief Services, Zambia; Andrew Tomkins, Institute of Child Health, University College, London; Rodah Zulu, National Institute of Science and Industrial Research, Zambia; Clinic Coordinator: Molly Chisenga; Clinical Officer: Joshua Siame; Data Manager: Hildah Banda Mabuda; Statisticians: Kathy Baisley, Helen Dale, Andrea Rehman; Research Fellows: Matthew Bates, Anne Mullen; Clinic Staff: Hellen Kangwa Bwalya, Margaret Chileshe, Priscilla Kangwa Kowa, Mabvuto Kumwenda, Munalula Likando, Sydney Mambwe, Mutinta Muzyamba, Anne Mwale, Lungowe Nyaywa; Laboratory Staff: Mirriam Kapambwe, Humphrey Bima, Laura Gosset, Louise Hackett, Abigail Jackson, Eric Njunju, Sydney Mwanza; Data Entry: Natalia Shampwaya, Concillia Kabanga; Drivers and Cleaners: John Chobo, Winford Kapumba, Charity Musonda, Philip Soko.

None of the authors has any conflict of interest regarding the material discussed in the paper.

\section{References}

1. Walker SP, Wachs TD, Meeks Gardner J, et al. (2007) Child development: risk factors for adverse outcomes in developing countries. Lancet 369, 145-157.

2. Grantham-McGregor S, Cheung YB, Cueto S, et al. (2007) Developmental potential in the first 5 years for children in developing countries. Lancet 369, 60-70.
3. Allen LH, Peerson JM \& Olney DK (2009) Provision of multiple rather than two or fewer micronutrients more effectively improves growth and other outcomes in micronutrient-deficient children and adults. J Nutr 139, 1022-1030.

4. Eilander A, Gera T, Sachdev HS, et al. (2009) Multiple micronutrient supplementation for improving cognitive performance in children: systematic review of randomized controlled trials. Am J Clin Nutr 91, 115-130.

5. Adu-Afarwuah S, Lartey A, Brown KH, et al. (2007) Randomized comparison of 3 types of micronutrient supplements for home fortification of complementary foods in Ghana: effects on growth and motor development. Am J Clin Nutr 86, 412-420.

6. Black MM, Baqui AH, Zaman K, et al. (2004) Iron and zinc supplementation promote motor development and exploratory behavior among Bangladeshi infants. Am J Clin Nutr $\mathbf{8 0}$, 903-910.

7. Faber M, Kvalsvig JD, Lombard CJ, et al. (2005) Effect of a fortified maize-meal porridge on anemia, micronutrient status, and motor development of infants. Am J Clin Nutr 82, 1032-1039.

8. Olney DK, Pollitt E, Kariger PK, et al. (2006) Combined iron and folic acid supplementation with or without zinc reduces time to walking unassisted among Zanzibari infants 5- to 11-mo old. J Nutr 136, 2427-2434.

9. Katz J, Khatry SK, LeClerq SC, et al. (2010) Daily supplementation with iron plus folic acid, zinc, and their combination is not associated with younger age at first walking unassisted in malnourished preschool children from a deficient population in rural Nepal. $J$ Nutr 140, 1317-1321.

10. Dhingra P, Menon VP \& Sazawal S (2004) Effect of fortification of milk with zinc and iron along with vitamins C, E, A and selenium on growth, iron status and development in preschool children - a community based double-masked randomized trial. In Reports from 2nd Congress of Pediatric Gastroenterology, Hepatology and Nutrition, 3-7 July 2004, Paris, Pediatr Gastroenterol 2004, 53-57.

11. Pollitt E, Saco-Pollitt C, Jahari A, et al. (2000) Effects of an energy and micronutrient supplement on growth and development in undernourished children in Indonesia: methods. Eur J Clin Nutr 54, S16-S20.

12. Famine Early Warning Systems Network Zambia (FEWS NET Zambia) (2006) Zambia Food Security Update September 2006. http://www.fews.net/docs/Publications/Zambia_200608 en.pdf (accessed May 2011).

13. Gitau R, Makasa M, Kasonka L, et al. (2005) Maternal micronutrient status and decreased growth of Zambian infants born during and after the maize price increases resulting from the southern African drought of 2001-2002. Public Health Nutr 8, 837-843.

14. United Nations International Children's Emergency Fund (2010) Complementary feeding. http://www.unicef.org/ nutrition/index_24826.html (accessed May 2011).

15. Filteau $S \&$ The Chilenje Infant Growth, Nutrition and Infection (CIGNIS) Study Team (2009) Micronutrient fortification to improve growth and health of maternally HIV-unexposed and exposed Zambian infants: a randomised controlled trial. PloS one 5, e11165.

16. World Health Organization and United Nations International Children's Emergency Fund (2010) Review of National Immunization Coverage 1980-2008: Zambia. http://www.childinfo.org/files/Immunization_summary_2008_r6.pdf (accessed May 2011).

17. Owino VO, Sinkala MM, Amadi B, et al. (2007) Acceptability, storage stability and costing of $\alpha$-amylase-treated maizebeans-groundnuts-bambaranuts complementary blend. J Sci Food Agric 87, 1021-1029. 
18. Owino VO, Kasonka LM, Sinkala MM, et al. (2007) Fortified complementary foods, with or without $\alpha$-amylase-treatment, increase hemoglobin but do not reduce breast milk intake of 9-month old Zambian infants. Am J Clin Nutr 86, 1094-1103.

19. Dewey KG \& Brown K (2003) Update on technical issues concerning complementary feeding of young children in developing countries and implications for intervention programs. Special issue based on a World Health Organization expert consultation on complementary feeding. Food Nutr Bull 24, 5-28.

20. MOST (2005) Fortification Basics: Maize Flour/Meal. http://www. mostproject.org/Updates_Feb05/Maize_Corn.pdf (accessed August 2010).

21. Tofail F (2006) Effect of food and micronutrient supplementation during pregnancy on subsequent development of infants in Bangladesh: a randomized trial. PhD Thesis, University College London.

22. Lennon EM, Gardner JM, Karmel BZ, et al. (2008) Bayley scales of infant development. In Encyclopedia of Infant and Early Childhood Development, pp. 145-156 [M Haith and J Benson, editors]. New York: Academic Press.

23. Carpenter JR \& Kenward MG (2007) Missing data in randomised controlled trials - a practical guide. http://www.haps bham.ac.uk/publichealth/methodology/docs/invitations/ Final_Report_RM04_JH17_mk.pdf (accessed August 2010).

24. Armitage P, Berry G \& Matthews JNS (2002) Statistical Methods in Medical Research, 4th ed. Oxford: Blackwell Science Ltd.

25. Filmer D \& Pritchett LH (2001) Estimating wealth effects without expenditure data - or tears: an application to educational enrolments in states of India. Demography $\mathbf{3 8}$, 115-132.

26. World Health Organization (2006) Child Growth Standards. www.who.int/childgrowth/software/en/ (accessed August 2010).

27. Rabe-Hesketh S \& Skrondal A (2008) Multilevel and Longitudinal Modeling Using Stata, 2nd ed. College Station, TX: Stata Press.

28. Grantham-McGregor SM, Walker SP \& Chang S (2000) Nutritional deficiencies and later behavioural development. Proc Nutr Soc 59, 47-54.
29. World Health Organization Multicentre Growth Reference Study Group (2006) WHO Motor Development Study: windows of achievement for six gross motor development milestones. Acta Paediatr Suppl 450, 86-95.

30. Monnot M (1998) Language development. In The Cambridge Encyclopedia of Human Growth and Development, pp. 251-252 [SJ Ulijaszek, FE Johnston and MA Preece, editors]. Cambridge: Cambridge University Press.

31. Grantham-McGregor SM \& Ani CC (1999) The role of micronutrients in psychomotor and cognitive development. Br Med Bull 55, 511-527.

32. McGrath N, Bellinger D, Robins J, et al. (2006) Effect of maternal multivitamin supplementation on the mental and psychomotor development of children who are born to HIV-1-infected mothers in Tanzania. Pediatrics 117, e216-e225.

33. Schmidt MK, Muslimatun S, West CE, et al. (2004) Mental and psychomotor development in Indonesian infants of mothers supplemented with vitamin A in addition to iron during pregnancy. Br J Nutr 91, 279-286.

34. Tofail F, Persson LA, El Arifeen S, et al. (2008) Effects of prenatal food and micronutrient supplementation on infant development: a randomized trial from the Maternal and Infant Nutrition Interventions, Matlab (MINIMat) study. Am J Clin Nutr 87, 704-711.

35. Black MM \& Matula K (2000) Essentials of Bayley Scales of Infant Development II Assessment. Essentials of Psychological Assessment Series. New York: Wiley.

36. Strauss E, Sherman EMS \& Spreen O (2006) Bayley Scales of Infant Development - Second Edition (BSID-II): Demographic Effect. In A Compendium of Neuropsychological Tests: Administration, Norms, and Commentary, pp. 120-121. Oxford: Oxford University Press.

37. Gladstone MJ, Lancaster GA, Umar E, et al. (2010) The Malawi Developmental Assessment Tool (MDAT): the creation, validation, and reliability of a tool to assess child development in rural African settings. Plos Med 7, e1000273.

38. International Zinc Consultative Group (2004) Assessment of the risk of zinc deficiency in populations and options for its control. Food Nutr Bull 25, 94S-203S. 